\title{
Pilot Study: Breaking the Virtual Boundary and Forging Communities of Practice through Virtual Worlds
}

\author{
Jegatheva Jay Jay Jegathesan
}

\begin{abstract}
D Virtual worlds are crossing and bridging boundaries between the virtual and the real, as well as creating dynamic communities across and between researchers, artists and filmmakers, among others. This paper is the result of a pilot study that points to three strands of investigation that have now been planned to be carried out over the coming two years. The first strand where preliminary questionnaire data were collected shows how positive perceptions can be formed of a physical institution after having experienced it in a virtual sense. The second strand, in which international focus groups were used, seems to indicate how communities of practice have developed within and between artists and film makers using 3D virtual worlds instead of through conventional approaches. The third strand, in which an international focus group was also used, also seems to indicate how a community of practice has developed and further shows how the use of 3D virtual technologies have allowed educators and researchers in educational institutions to increase the breadth, depth, diversity and frequency of their research collaborations as compared to periods prior to them using 3D virtual technologies. More in-depth empirical studies on all of this will follow.
\end{abstract}

Index Terms-3D Art, communities of practice, machinima, second life, virtual worlds.

\section{INTRODUCTION}

Whatever you can do or dream you can, begin it. Boldness has genius, power, and magic in it. Begin it now.

So said Johann Wolfgang von Goethe [1], and it is with that spirit that educators and researchers have over the years immersed themselves in creating, participating in and researching $3 \mathrm{D}$ virtual worlds.

Virtual world research goes as far back as 1965 when Ivan Sutherland first conceived, built and displayed some of the first 3D computer graphics [2]. This has gathered momentum over the years, with the advent of fully immersive 3D virtual environments available on home desktop computers since the turn of the century, through the likes of Second Life (SL), Blue Mars and Inworldz. The research that has mushroomed, covers a plethora of areas including among others, experimental psychology [3], marketing [4], aerospace [5], film [6], healthcare [7], art \& design [8] and even teaching and learning pedagogy [9], where 47 academics from 28 Australian higher education institutions joined forces .

For this paper, virtual worlds are described as three-dimensional, immersive graphical environments through which individuals and groups can interact in real

Manuscript received July 3, 2013; revised September 15, 2013.

J. Jegathesan is with the School of Physics and founder of the 3D virtual presence of the University of Western Australia, WA 6009, Australia (email: jay.jay@uwa.edu.au). time, through 'avatars' or animated characters that move through 3D virtual space [10], [11].

When introducing 3D virtual worlds, especially to audiences which had hitherto little or no experience with them, it was noticed that having something the viewer was familiar with when seeing a 3D virtual world for the first time, for instance an iconic building in a university [12], helped in focusing the mind of the viewer and creating greater interest in the other facets of 3D virtual worlds which sometimes go well beyond the realm of the 'real', and helping to make the virtual, in essence, real and tangible.

Research has found that there is feelings of 'presence' in virtual worlds [5], as well as a merging of the virtual and real, where, the virtual world and the real world, while complete in and of themselves, are both enriched by the ability to mutually reflect, influence and at times almost seem to merge into one another [13]. This blurring of the boundaries between virtual and real is due to the increasing ability of virtual environments to replicate the sensory information of the physical world causing a suspension of disbelief [14].

A lot of the above research however, was theoretically based, and this led to the first strand of investigation in this paper, and that is to empirically test if perceptions of a virtual environment can have a direct impact on perceptions of the real environment that the virtual represents.

Dovetailing to the second and third strands, Jensen [15] put it beautifully

"...the encounter with the computer is transformed from an experience of a two-dimensional interface, which can be clicked on, to the experience of a space in which the user feels a presence and a community with other people; and correspondingly, that the encounter with the Internet tends to change from an experience of a web of linked 2D-documents, to an experience of a galaxy of interconnected 3-dimensional Virtual Worlds."

The clarion call of community was one that was echoed in numerous papers [6], [11], [12], [16]-[18], looking at 3D virtual art and film (known in this context as 'Machinima', which is animated film shot in real time [12] within a virtual world or a 3D graphics engine) as well as papers which referenced research collaborations between tertiary institutions [7], [9] using virtual worlds. This put a spotlight on the concept of 'Communities of Practice' (CoP), conceived in 1991 [19] by cognitive anthropologists, Jean Lave and Etienne Wenger.

Wenger [20] describes communities of practice as "groups of people who share a concern or a passion for something they do and learn how to do it better as they interact regularly" and offers that three characteristics are crucial in determining if a community is indeed a $\mathrm{CoP}$, these being the domain, the community, and the practice 


\section{[21]-[23].}

CoP research has been carried out in numerous fields ranging from knowledge sharing \& knowledge management [24], education and languages [25] organizational practice [26], and the arts [8] to name but a few.

Missing from the body of work however are empirical studies determining the existence of $\mathrm{CoP}$, in particular for those using 3D immersive virtual environments, and how these CoP impact upon those who may have been part of these CoP. Gaimster [8] explained that with virtual worlds there exist tools to create protected environments where participants are known to each other or where membership can be moderated, helping to form a sense of community. Such an environment was created by the University of Western Australia (UWA) in 2009 [18] to cater to research, teaching, art and machinima. This has led to UWA becoming recognized as the leading university within, Second Life, for the areas of 3D virtual art and machinima in this immersive environment that hosts more than 500 educational institutions [6], [12], [16], [27], [28]. Ling [11] explained, "UWA, with its consortium of partners and sponsor groups, has provided a nexus for energizing new art and has provided what has been a critical stabilizing influence in the world of virtual art. An essential aspect of this work is community."

Research thus far strongly indicates in a qualitative sense that community is a vital part of the fabric that weaves artists and filmmakers together in virtual worlds, and has indicated further the pivotal role played by UWA in a virtual world that comprises more than 500 art galleries, collectives and communities. Other research [7], [9], again in a qualitative sense points to the $\mathrm{CoP}$ that has been building between researchers using 3D virtual worlds.

This paper thus begins the empirical examination of how perceptions of the virtual impact on perceptions of the real, and sets the stage for an empirical evaluation of the $\mathrm{CoP}$ within and between communities of 3D artists, filmmakers and researchers who use virtual worlds.

\section{METHOD}

\section{A. Strand 1: Perceptions of the Virtual and Real}

A short questionnaire was designed employing a Likert Scale [29], with two demographic questions (age \& gender), two questions relating to a presentation on $3 \mathrm{D}$ virtual worlds that respondents would have just seen, one pertaining to their thoughts on 3D virtual technologies, and one asking to what extent if any, their perceptions of what they saw in the virtual impacted on the real. This was followed by a question asking respondents to describe their experience in a single word followed by an open ended question asking for any comments they wished to share.

The author has for a number of years been invited to speak on the use of 3D virtual worlds in various contexts and between December 2012 and April 2013 began inviting those who attended the talks and presentations to complete the survey. During this period, those attending the talks had primarily been high school and university students and their teachers.

The survey was voluntary, and anonymous, with no identifying information collected of any of the respondents. Questionnaires were distributed immediately following each talk (of which there were 7). These responses were then transferred to SurveyMonkey to assist with analysis. A total of 191 respondents completed the survey.

\section{B. Strand 2: CoP Artists and Filmmakers}

One of the greatest strengths of virtual worlds, indeed of Second Life which has the largest number of users of any of the user created 3D virtual worlds, is the ability to almost instantly connect to people from all corners of the globe [12].

Working with the strength of the medium, it was decided to run 2 international focus group sessions on the $14^{\text {th }}$ and $15^{\text {th }}$ of June 2013 (see Fig. 1 on following page). Also, it was decided at this stage to group 3D artists and filmmakers as recent research [6], [21] pointed to the developing of a mutual dependence between between the two that was almost becoming a genre of its own, with digital art being ephemeral in nature and confined to the virtual world, but with machinima preserving the art and re-presenting its impact beyond the virtual boundary.

Focus Group 1 (FG1), comprised of members of a number of the biggest art and film groups in Second Life including Second Life Artists Group, UWA 3D Art \& Design Challenge Group, Machinimatographers Group and the Art \& Artist Network, and came together as a result of a request made through the group communication channels available in the virtual world. This was a group of 12 , including 7 from the United States (New Jersey, Oregon, Seattle, Indiana, New Orleans, North Carolina \& Oklahoma), 2 from Australia (Melbourne \& Sydney), and one from each of Germany (Nurnberg), the UK (London) and South Africa.

Focus Group 2 (FG2) was constructed via a similar method. This was a group of 13, including 5 from the USA (Texas, New Hampshire, Chicago, Los Angeles \& undisclosed), 3 from the UK (London, London \&, Dorset), 2 from Australia (Perth \& Melbourne) and one each from Germany (Berlin), Canada (Toronto) and Denmark.

Data were collected during the focus group through two methods. First, participants discussed questions introduced by the researcher, subsequently, at the end of the session, they were asked to put their thoughts to paper in a paragraph or two addressing the same questions.

The questions were:

1) Has using $3 \mathrm{~d}$ virtual worlds helped create or increase a sense of community for you?

2) Has the use of this technology increased the frequency, number and diversity of communications and collaborations you have had with respect to art and/or film?"

\section{Strand 3: CoP - Educators \& Researchers}

Operating with the same reasoning as for artists and filmmakers, an international focus group session was also held for Educators and Researchers (Focus Group 3 - FG3)

This group came together on the $16^{\text {th }}$ of June as a result of a request sent through group communications channels of the Trans-Tasman based Virtual Worlds Working Group $(V W W G)$ as well as the Real Life Education in Second Life Group.

The was a group of 8 , with 4 educators and researchers 
based in Australia (Sydney, Brisbane, Melbourne \& New England), 3 based in the United States (Boston, Seattle \& Illinois) and one from the UK (Oxford).

This focus group worked the same way as the first two; however the questions they were asked to respond to were as follows:

1) Has using $3 d$ virtual worlds helped create or increase a sense of community for you?

2) Has the use of this technology increased the frequency, number and diversity of your research collaborations?",

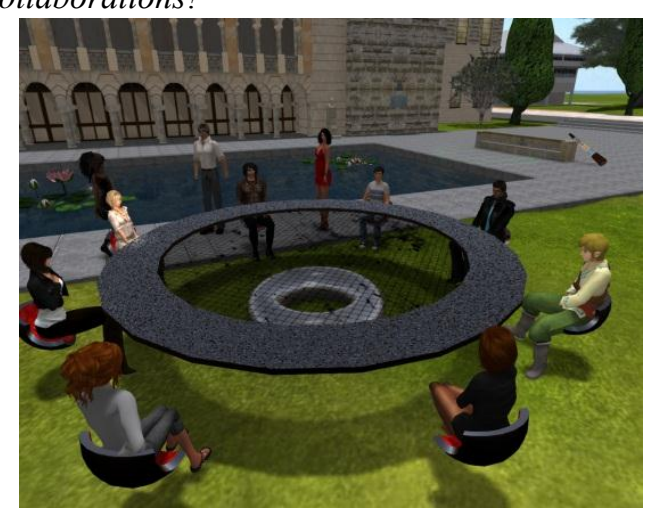

Fig. 1. A focus group in action @ UWA in Second Life.

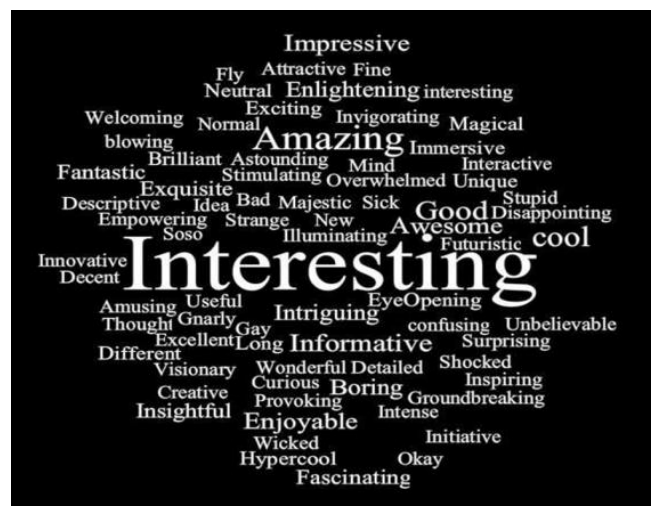

Fig. 2. Word cloud responses to Question 7.

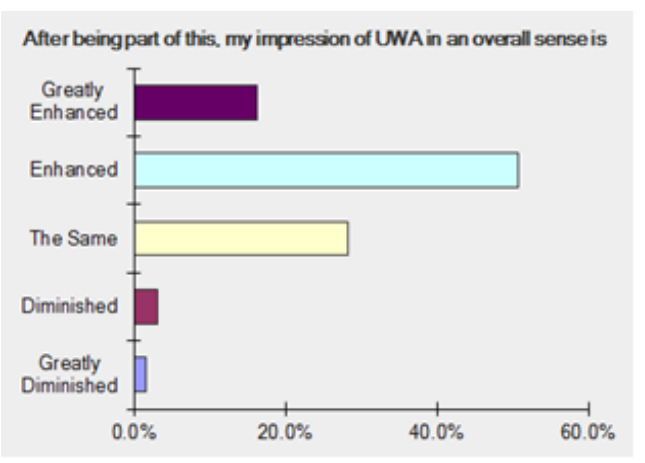

Fig. 3. Real impressions impacted by the virtual.

\section{RESULTS}

\section{A. Strand 1: Perceptions of the Virtual and Real}

The survey was answered by 191 respondents. $51.8 \%$ were between 13-15 years of age, with the 16-18 year age bracket being the next largest cohort with $25.7 \%$. In terms of gender, $60.7 \%$ of respondents were male with females making up the remaining $39.3 \%$

Question 3 asked if the respondents found the presentation interesting, and $74.3 \%$ responded that they agreed or strongly agreed. This is consistent with responses to Question 7 which was open ended and asked for a one word description of the entire experience, and as can be seen via the word cloud in Fig.2, the experience was very positive, with $81 \%$ being positive words or emotive descriptors, $11 \%$ being neutral and only $6 \%$ being negative words or emotive descriptors ( $2 \%$ non-responses).

To Question 4, 38.2\% agreed (20.4\% strongly agree) that the experience made them want to learn more about virtual worlds, with $15.7 \%$ disagreeing or strongly disagreeing. $46.6 \%$ agreed or strongly agreed that 3D immersive technologies would have a great impact on their lives, with $29.8 \%$ being neutral and the rest either disagreeing or strongly disagreeing.

Question 6, the pivotal question, asked respondents if their impressions of UWA in an overall real world sense had been impacted by their experience of UWA through the virtual. Here, as per Fig.3, 67\% of respondents indicated that their impressions were either enhanced or greatly enhanced, with $4.7 \%$ responding that their impressions were diminished or greatly diminished, with no change being reported by the rest. All in $71.7 \%$ reported changes to their real world impressions after having experienced UWA through the virtual, increasing to $75 \%$ when filtering out the 13-15 age group.

\section{B. Strand 2: CoP Artists and Filmmakers}

Across both focus groups, the themes and sentiments coming through were remarkably similar, and these were of an expanded sense of community, the disintegration of geographic boundaries, diminished feelings of working in isolation, achieving what they thought impossible, the almost limitless creative freedom and a worldwide audience. Figures 4 through 6 show examples of immersive, interactive and sculpture based 3D virtual art.

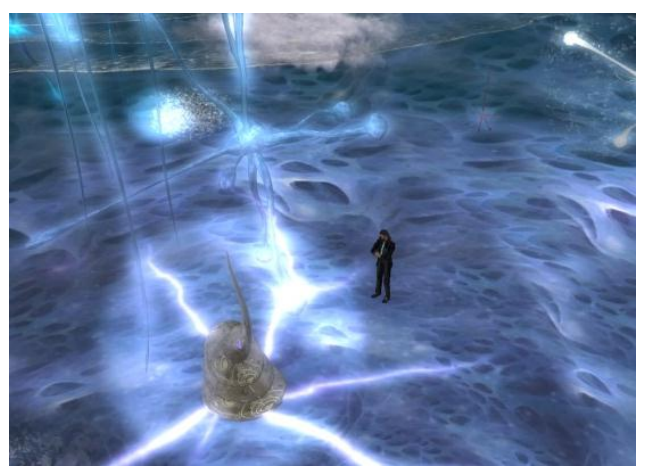

Fig. 4. Avatar of the author within 'Neron Sphere', an immervive 3D artwork by French artist Shenn Coleman.

It is best the participants speak for themselves. Here are extracts from a selection of responses.

"SL allows artists from all walks of life from countries spanning the globe to come together for a common purpose that brings our art to people who would never have otherwise seen it. I can build on a scale with materials I could never acquire, and defy the laws of physics that constrain me in real life. The support, the criticism, the many projects that I did in this virtual space gave me greater confidence and honed certain skills that became vital in my real life" (Respondent FG1-1) 
"Virtual worlds enable artists, writers and filmmakers to get things done. You are able to find like-minded individuals and teams easily. The community of artists is enhanced and strengthened by shared knowledge." (Respondent FG1-9)

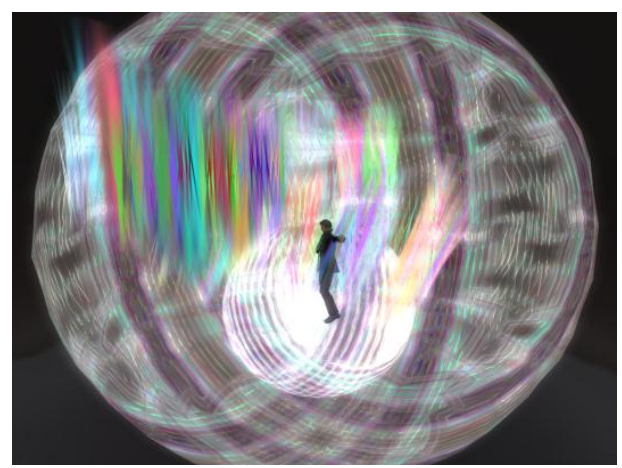

Fig. 5. Avatar of the author within 'Tendrils', an interactive 3D artwork that reacts to the presence of avatars by Australian artist Glyph Graves.

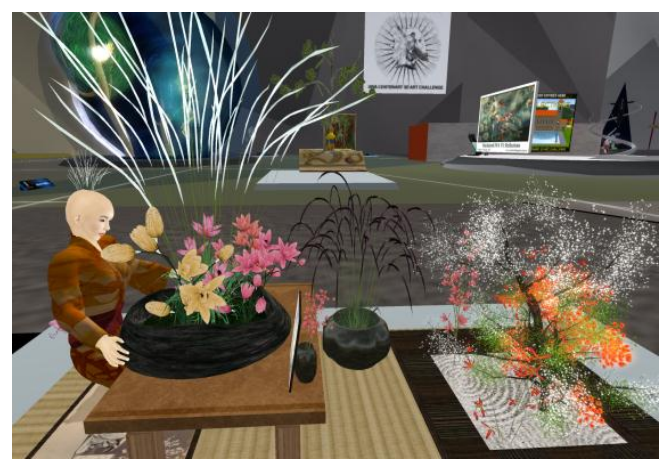

Fig. 6. Digital sculpture by Japanese artist Mitsuko Kyotori on display at the UWA 3D art gallery.

"SL gives me a great sense and feeling of belonging to an amazing and fantastically diverse community from around the world...I have immersed, interacted, exhibited and viewed artworks and builds that only a virtual world can make possible for us to experience." (Respondent FG1-10)

"As an oil painter my career involves spending about a year building up a series of paintings in my studio to be shown publicly in the gallery for one month duration. For 11 months I work in solitude with little interaction. The one month show brings me into contact predominately with locals from Toronto for the opening night and then over the course of the month long exhibit. In contrast, working in a virtual world has brought me into contact with people from around the globe, creating exposure and opportunities that are not available in the same manner with my painting career." (Respondent FG2-2)

"As a platform for truly global creative collaboration, as a vehicle for expressing ideas, sharing pioneering advancements and discovering the hidden imaginations of millions of people, Second Life is unbeatable. The sense of community within Second Life is all pervasive, and whilst we might not know personally the real people behind the screens that operate our avatars, one thing is for sure: we can emotionally, mentally, spiritually and intellectually connect with people them on a very real level. And this is perhaps the greatest gift that SL has ever given us" (Respondent FG2-7)

"In real life I have found that I have been limited to work with artists who live close to me, but in virtual worlds such as Second Life I can collaborate with artists from all over the world...knowing that other artists from all around the world also take this way of making art seriously, helps me to believe in it as a new medium" (Respondent FG2-9)

"Using a Virtual World has opened up artistic opportunities that would not otherwise have been available to me by attracting and incorporating the best people (no matter what country they live in) for a project. Virtual worlds bring together people from across the globe; a sense of global community not found before VW's, and affords a better understanding of individual cultures." (Respondent FG2-13)

\section{Strand 3: CoP - Educators and Researchers}

With this focus group, the two strongest ideas coming through were global collaboration and increased research linkages. Once again, here are extracts from a selection of responses:

"Virtual worlds facilitate collaboration across many actual world boundaries in all the ways that other networked communications do, and more. As an artist, scholar, and teacher, I've been able to work in real-time with people from all over the world, many of whom I probably would never have met in my everyday life because of where we live and the different social and professional circles in which we move. Virtual worlds have expanded my experience of community and collaboration exponentially. "(FG3-3)

"...we now have schools/researchers in a number of countries around the world (including Singapore and Italy) who want to use the (virtual) worlds in their classrooms...it has opened up possibilities where geographical location is no longer an inhibitor and costs of travel and lost travel time can be avoided" (FG3-4)

"For me, the use if virtual worlds have opened up the possibility of global film-making to an incredible degree. I present a programmer with a presenter who sits in his studio 30 miles away - and yet we walk down the same street, talking. And we're directed by someone on the East Coast of America, and filmed by people in Germany, the UK, the US and Australia." (FG3-2)

"The education potential at such a low cost allowed me limitless learning, that is to say, time and dedication were my hurdles, not money...(to those who)... tell me 'the cost of education is too high.' I reply, 'the cost of ignorance can't be measured.' The future of virtual learning has the ability to be global, uniting countries, and cultures in a classroom that has no boundary!" (FG3-8)

\section{DISCUSSION}

Ling [11], explained that the electronic projection of the self, or the virtual self, cannot of course exist without the atomic self, yet the virtual self can appear to be real. For many decades since virtual worlds were envisioned, achieving a sense of realness or presence had been a goal too hard to accomplish. Almost 20 years ago, Biocca and Delaney [30] offered that for the virtual to feel real, there needed to be speech, eye movements, facial expressions, hand gestures and body language with Jelfs and Whitelock [5] finding that audio feedback was one of the most 
important features to engender a sense of presence within the virtual. All of this, not widely available then, is an intrinsic part of the 3D virtual worlds of today like Second Life.

The presentations conducted in the virtual world as described in Strand 1, had the advantage of all of these aspects required to achieve a sense of realness, including audio feedback, as the presentation featured live discussions with people from numerous countries around the world via their avatars. This is possibly why $74.3 \%$ of those attending agreed or strongly agreed that the presentations were interesting with $81 \%$ providing positive responses when asked to describe their experiences with a single word.

What has often been theoretically predicted seems to be being empirically supported with the date presented in this paper, which perceptions of the virtual can and do impact on perceptions of the real? This realness can be felt by participants being given their first experiences of the virtual world and is probably developed and enhanced for those who use virtual worlds extensively. The presence of strong credible institutional presences within the virtual world, such as the UWA or the VWWG, may result in the creation of focal points for the flourishing of Communities of Practice. [24]

It is important to note that for Strand 1, the results are preliminary, as we have at these stage only 191 respondents, of which $51.8 \%$ are in the 13-15 age groups, and there exists a $20.4 \%$ gender gap imbalance skewed in favor of males. Only preliminary analysis has been done at this stage, and further analysis including margin of error, and so on will be completed once a full complement of responses is gathered over the next 2 years (the plan calls for approximately 2,000 survey responses).

With Strand 2, focus groups 1 and 2 were unanimous in supporting the likes of Gaimster [8] and Hearns and Jegathesan [28] who proclaimed that virtual worlds were ideal learning environments as they allowed for collaboration and participation in communities on a global scale. This was seen across every one of the 25 participants who made up both focus groups, all of whom expressed the feeling of a profound sense of community. Virtual world activities run by major institutions such as the UWA “...train artists in a dynamic, stimulating, supportive and collaborative environment, where the learner takes the leading role." [28]

Wenger [20] spoke of how The Impressionist artists did not work together in the practice of their profession, rather they used to meet in studios and cafes to discuss their creations and their art, and it is these interactions that made them a CoP. It is seen that now, for those like the oil painter in Toronto (FG2-2), virtual worlds are creating this CoP, with a global venue replacing the studios and cafes of old in Paris, Venice, London and the like.

Within these focus groups the three characteristics determining a CoP [20] were evident. The domain, the belief in the collective competence and the ability for mutual learning was clear. Similar to considerable recent research [6], [12], [16], [28], the community aspect was expressed strongly by a number of participants. The practice was also evident, with a shared repertoire of resources having been built over time.
Another important lesson learned from focus groups 1 and 2 was that although they are closely aligned, we should investigate the art community, and the machinima (virtual film) community as two separate CoP. This message came across very strongly in the discussion, and seemed to be an echo of what Wenger [21] described, "Communities of practice...remain important social units of learning even in the context of much larger systems. These larger systems are constellations of interrelated communities of practice." Jegathesan [6] also observed how UWA's collaborative efforts led to the intertwining of the "universes" of $3 \mathrm{D}$ artists and filmmakers.

Constellations of interrelated communities of practice, is what will be investigated over the next two years, with empirical studies planned to investigate the existence of the three characteristics and the degree to which collaboration and community has been facilitated within these communities, as well as the research community, which will be discussed next.

VW's are a potential boon for researchers, as they can provide an environment that is global, facilitating the creation of labs and learning spaces where potentially research subjects can be found in the thousands for a much lower cost than trying to cross geographical boundaries through conventional methods [10], or a small number of research subjects from a diverse set of cities worldwide for focus group studies as in focus group 3 .

Education groups using virtual worlds; like the VWWG have also found that the collaboration within the group has been increased over the years since its inception [9]. Moreover, the competencies of those in the group, for example when it comes to publishing their findings, have been assisted by working together through the community. This is the only forum through which such a diverse group of academics from such a wide range of international universities and educational institutions meet, collaborate, share ideas and discuss on such a regular basis (every two weeks). This degree of connectedness is enabled by the low cost, ubiquitous availability, and relatively simple technology requirements aside from a computer and a stable internet connection.

Focus group 3 pointed strongly to what was theorized in terms of virtual worlds allowing for an increased breadth, depth and frequency of collaboration between researchers and those involved in education and to what could be seen among groups linked to education that used virtual worlds.

The findings presented in this paper point to the need for a more refined empirical study to first of all determine that it is indeed a $\mathrm{CoP}$ that has formed, in this context, to explore the nature of the $\mathrm{CoP}$ and to test the extent to which research collaboration has been facilitated and fostered by participation in virtual worlds.

\section{CONCLUSION}

The significance of this work is that it provides data that supports the idea that the virtual impacts on the real, and sets the stage for an investigation of three major communities within virtual worlds, that of artists, filmmakers and educators through the lens of Communities of Practice. It further points to the existence of 
constellations of interrelated CoP within virtual worlds, which will also be investigated.

\section{REFERENCES}

[1] J. Goethe. (June 2013). Inspiration Peak. [Online]. Available: www.inspirationpeak. com/cgi-bin/search.cgi?search=Goethe

[2] I. Sutherland, "The ultimate display," in Proc. the International Federation of Information Processing Congress, vol. 2, pp. 506-508, 1965.

[3] J. Loomis, J. Blascovich, and A. Beall, "Immersive virtual environment technology as a basic research tool in psychology," Behavior Research Methods, Instruments \& Computers, vol. 31, no. 4 pp. 557-564, 1999.

[4] W. Halvorson, M. Ewing, and L. Windisch, "Using second life to teach about marketing in second life," Journal of Marketing Education, vol. 33, no. 2, pp. 217-228, 2011.

[5] A. Jelfs and D. Whitelock, "The notion of presence in virtual learning environments: What makes the environments 'real'," British Journal of Education Technology, vol. 31, no. 2, pp. 145-152, 2000.

[6] P. Johnson, D. Pettit, and J. Jegathesan, "Celebrating Machinima: It's Show Time!" in Machinima: The Art and Practice of Virtual Filmaking, P. Johnson and D. Pettit (Eds.), North Carolina, McFarland \& Company Inc., 2012, ch. 8, pp. 165-174.

[7] M. McDonald, T. Ryan, J. Sim, J. James, P. Maude, S. Scutter, and D. Wood, "Multidiscipline role play in a 3D virtual learning environment: Experiences with a large cohort of healthcare students," in M. Brown M. Hartnett and T. Stewart (Eds.), Future Challenges, Sustainable Futures, Proceedings Ascilite Wellington, pp. 622-632, 2012.

[8] J. Gaimster, "Reflections on Interactions in virtual worlds and their implications for learning art and design," Art, Design \& Communication in Higher Education, vol. 6, no. 3, pp. 187-199, 2008.

[9] B. Gregory, S. Gregory, D. Wood et al., "How are Australian higher education institutions contributing to change through innovative teaching and learning in virtual worlds," in G. Williams, P. Statham, N Brown, \& B.Cleland (Eds.), "Changing demands, changing directions," Proceedings Ascilite Hobart, pp. 475-490, 2011.

[10] W. Bainbridge, "The scientific research potential of virtual worlds," Science, vol. 317, pp. 472-476, July 2007.

[11] F. Ling, "Art, creativity and virtual society," in G. Assorina and O. Kompaniets (Eds.), Partnership of Business and Education in the Regional Innovation Development, in Proc. 10th International Scientific and Practical Conference, Tver, vol. 10, pp. 11-15, 2011.

[12] S. Highley and J. Jegathesan, "In three dimensions: Art, machinima and the virtual university," The International Journal of Interdisciplinary Social Sciences, vol. 7, issue 2, pp. 44-57, 2013.

[13] J. Lifton and J. Paradiso, "Dual reality: Merging the real and virtual," in Facets of Virtual Environments, F. Lehmann-Grube and J. Sablatnig (Eds.), LNICST 33, pp. 12-28, 2010.

[14] M. Shapiro and D. McDonald, "I'm not a Real Doctor, but I play one in virtual reality: Implications of virtual reality for judgments abou reality," Journal of Communication, vol. 42, no. 4, autumn, 1992.

[15] J. Jensen, "3D inhabited virtual worlds interactivity and interaction between avatars, autonomous agents, and users," in Proc. WebNet World Conference on the $W W W$ and Internet, Chesapeake, VA, AACE, pp. 19-26, 1999.

[16] M. Hearns and J. Jegathesan, "Facilitating art education: The UWA arts challenges," International Journal of Virtual and Personal Learning Environments, vol. 4, no. 2, pp. 107-123, April-June 2013.
[17] J. Jegathesan, "Breaking down the barriers: Machinima," Journal of Gaming and Virtual Worlds, vol. 4, no. 1, pp. 07-109, 2012.

[18] J. Jegathesan, "The UWA 3D Open Art Challenge: 3D Virtual Art Case Study," in G. Assorina and O. Kompaniets (Eds.), "Partnership of Business and Education in the Regional Innovation Development," Proceedings 10th International Scientific and Practical Conference, Tver, vol. 10, pp. 15-18, 2011.

[19] J. Lave and E. Wenger, Situated Learning: Legitimate Peripheral Participation, Cambridge University Press, Cambridge, 1991.

[20] E. Wenger. (May 2013). Communities of practice, a brief introduction. Communities of Practice. [Online]. Available: http://www.ewenger.com/theory/

[21] E. Wenger, "Communities of practice and social learning systems," Organization, vol. 7, no. 2, pp. 225-246, 2000.

[22] M. Smith. (2003). Jean Lave, Etienne Wenger and communities of practice. The Encyclopedia of Informal Education. [Online] Available: http://www.infed. org/biblio/communities_of_practice.htm

[23] E. Wenger, Communities of Practice: Learning, Meaning, and Identity, Cambridge University Press, 1998.

[24] A. Ardichvili, V. Page, and T. Wentling, "Motivation and barriers to participation in virtual knowledge-sharing communities of practice," Journal of Knowledge Management, vol. 7, issue 1, pp. 64-77, 2003.

[25] C. Kimble, P. Hildreth and I. Bourdon. Communities of practice: Creating learning environments for educators. [Online]. Available: http://www.chris-kimble.com/CLEE/ToC.html

[26] J. Liedtka, "Linking competitive advantage with communities of practice," Journal of Management Inquiry, vol. 8, no. 1, pp. 5-16, 1999.

[27] J. Jegathesan, "Worlds of Wonder: Teaching, Art, Research, Short Film and Architecture at the University of Western Australia's 3D Virtual World", SCIOS Journal of the Science Teachers' Association of Western Australia, vol. 48, no. 3, pp. 8-9, September 2012.

[28] M. Hearns and J. Jegathesan, "The university of Western Australia 3rd art challenges: Virtual promotion of an art community," The International Journal of Interdisciplinary Social Sciences, vol. 7.

[29] R. Likert, "A technique for the measurement of attitudes," Archives of Psychology, vol. 22, no. 140, pp. 1-55, 1932.

[30] F. Biocca and B. Delaney, "Immersive virtual reality," in F. Biocca and M.R. Levy (Eds.), Communication in the Age of Virtual Reality, Hillsdale, NJ, Erlbaum, pp. 57-124, 1995.

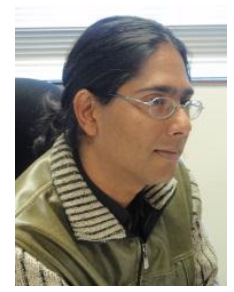

Jay Jay Jegatheva Jegathesan was born in Malaysia in 1973, and migrated to Australia in 2004. Jay Jay holds a Bachelor of Commerce (Hons) degree from the University of Western Australia (UWA), majoring in management and marketing.

He has since 2008, been the manager of the School of Physics at UWA and is the founder and leader of the UWA presence in 3D virtual worlds. His research interests extend to looking at groups of artists, film makers and educators through the lens of Communities of Practice, as well as investing how perceptions of institutions when experienced through virtual technologies are able to impact on and influence perceptions of the real.

Mr Jegathesan was shortlisted into the top 10 for the 2010 International Linden Prize for his work using virtual technologies; he has also served as a review panel member for the Australasian Journal of Educational Technology (AJET), Springer, and United Kingdom and as an associate editor for The International Journal of Interdisciplinary Social Sciences. 